\title{
The influence of clonal diversity and intensity-dependence on trematode infections in an amphipod
}

\author{
D. B. KEENEY ${ }^{1,2}$, K. BRYAN-WALKER ${ }^{1}$, N. KHAN ${ }^{1}$, T. M. KING ${ }^{1}$ and R. POULIN ${ }^{1 *}$ \\ ${ }^{1}$ Department of Zoology, University of Otago, P.O. Box 56, Dunedin 9054, New Zealand \\ ${ }^{2}$ Department of Biological Sciences, Le Moyne College, 1419 Salt Springs Road, Syracuse, NY 13214-1301, USA
}

(Received 3 September 2008; revised 19 October and 13 November 2008; accepted 14 November 2008; first published online 21 fanuary 2009)

\section{SUMMAR Y}

Individual animals are often infected not only by different parasite species, but also by multiple genotypes of the same parasite species. Genetic relatedness among parasites sharing a host is expected to modulate their strategies of resource exploitation, growth and virulence. We experimentally examined the effects that genetic diversity and infection intensity had on host mortality, infectivity and growth of the marine trematode Maritrema novaezealandensis in amphipod hosts. The presence of 2 versus 1 parasite genotype during infection did not influence subsequent host mortality, had different effects on infectivity among genotypes and did not influence growth or variation in parasite growth. Density-dependent growth reductions revealed that the number of parasites infecting a host was more important than their genetic relatedness. Temperature, host size, and host sex influenced the degree to which density-dependent factors affected parasite growth. Our results suggest that the effects of parasite relatedness vary among parasite genotypes in this trematode species, and reveal that many factors play an important role during parasite development and transmission.

Key words: amphipods, clonality, growth, Maritrema novaezealandensis, microsatellites.

\section{INTRODUCTION}

A fundamental property shaping the ecology and evolution of animal life history strategies as well as their social and reproductive behaviour is the genetic relatedness among interacting individuals (Hamilton, 1964; Dugatkin, 1997; Hughes et al. 2008). The relatedness of individuals can determine the selective advantages or disadvantages that different lifehistory strategies and behaviours confer to the individuals adopting them. For example, Hamilton's (1964) theory of kin selection demonstrates how organisms gain inclusive fitness via the reproduction of related individuals and has been used to explain the evolution of a diversity of biological phenomena and behaviours such as altruism and selfishness (Griffin and West, 2002).

The relatedness of interacting parasites may play an important role in many aspects of their biology, including their infectivity to hosts (Jager and Schjorring, 2006; Rauch et al. 2008) and resource utilization within hosts (Frank, 1992, 1996; Parker et al. 2003). Parasite populations are typically divided into infrapopulations consisting of all of the conspecific individuals infecting the same individual host (Margolis et al. 1982), which therefore share an intimate association with each other. The fate of the host affects all individual parasites in this host; it

* Corresponding author: Department of Zoology, University of Otago, P.O. Box 56, Dunedin 9054, New Zealand. Tel: +643479 7983. Fax: +643479 7584. E-mail: robert.poulin@stonebow.otago.ac.nz is their habitat as well as their only resource. The growth and host exploitation strategy adopted by an individual parasite affects its individual fitness, but if it is closely related to conspecific parasites in the same host, its actions also affect its inclusive fitness. Individual strategies have consequences for the group, and it is in this context that parasite evolution occurs. Many models suggest that virulence and growth rate of microparasites are affected by withinhost parasite genetic variability (Frank, 1996; Chao et al. 2000; Brown et al. 2002). For macroparasites that do not multiply within the host, relatedness among parasites sharing a host may also matter, influencing both patterns of resource use and growth (Parker et al. 2003).

The life cycles of trematodes (Platyhelminthes, Subclass Digenea) typically include 1 or more intermediate hosts with larval parasites often achieving their final transmission to a vertebrate definitive host through predation (Bush et al. 2001). Larval trematodes are aggregated among their intermediate hosts, forming discrete groups within intermediate hosts of 1 to many individuals. Within molluscan first intermediate hosts, asexual reproduction can produce thousands of genetically identical larvae (cercariae) that leave the molluscan host and infect second intermediate hosts (becoming metacercariae). This sets the stage for metacercariae to share second intermediate hosts with genetically identical as well as genetically distinct conspecifics. The majority of empirical studies on trematodes have examined schistosomes that are atypical digeneans in being dioecious and having cercariae shed from snails that 
directly penetrate definitive hosts. These studies suggest that mixed-genotype infections within snails are characterized by increased parasite reproduction rate and virulence (potentially resulting from increased host defence costs), but that less virulent genotypes may have a competitive advantage when multiple infections are common (Davies et al. 2002; Gower and Webster, 2005). In addition, competition among co-infecting Diplostomum pseudospathaceum genotypes produced lower parasite loads in fish second intermediate hosts (Rauch et al. 2008). These results indicate that the genetic diversity of trematode infections could be an important factor influencing host fitness, parasite growth and infectivity.

In addition to the influence of the genetic diversity of infections, density-dependent reductions in parasite growth can occur from host resource limitation or immune responses (Keymer, 1982; Shostak and Scott, 1993). Reductions in trematode growth have been documented when increasing numbers of metacercariae share the same intermediate host (Sandland and Goater, 2000; Brown et al. 2003). Theoretically, the optimal size that a parasite should reach within its intermediate host also depends on its relatedness to other parasites in the same host (Parker et al. 2003). Resource monopoly is not necessarily the best strategy among identical genotypes sharing a host and in these circumstances an individual parasite may be less aggressive in its exploitation of host resources.

In this study we use an experimental approach to examine the influence of both genetic relatedness and density-dependent factors on host mortality, parasite infectivity, and within-host parasite growth in the marine trematode Maritrema novaezealandensis (Microphallidae) and its amphipod second intermediate host Paracalliope novizealandiae. In nature, metacercariae of this trematode species generally occur in mixed-clone infections inside second intermediate hosts (Keeney et al. $2007 a, b$ ), but the significance of this observation remains unknown. We determine (1) if host mortality differs following exposure to single- $v s$ double-genotype parasite infections; (2) if the number of parasites successfully infecting hosts differs between single- $v s$ doublegenotype parasite infections; (3) if individual parasites grow faster or show more variation in their growth within hosts when they share a host with different conspecific genotypes vs identical genotypes; and (4) if growth rates or variation show density-dependent effects and if these are influenced by the genetic identity of the parasites.

\section{MATERIALS AND METHODS}

\section{Study system}

The marine trematode $M$. novaezealandensis is common within shallow coastal bays throughout the South Island of New Zealand. It utilizes the mud snail Zeacumantus subcarinatus as a first intermediate host, several crustaceans, including the crab Macrophthalmus hirtipes and amphipod P. novizealandiae, as second intermediate hosts, and shorebirds as definitive hosts (Martorelli et al. 2004). Once cercariae are shed from snails and penetrate a second intermediate host, the larval parasite increases in size and encysts, forming fully developed metacercariae in approximately 4-5 weeks (Martorelli et al. 2004). The life cycle is completed when a bird consumes the parasite along with its crustacean host, with sexual reproduction then taking place within the bird's gut.

\section{Snail screening}

Approximately 200 Z subcarinatus snails were collected from Lower Portobello Bay, South Island, New Zealand on 4 November 2006. Fifty snails were haphazardly selected and screened to identify single-genotype $M$. novaezealandensis infections. Individual snails were screened by being placed into $60 \mathrm{~mm}$ Petri dishes containing $0 \cdot 22 \mu \mathrm{m}$ filtered seawater at $25{ }^{\circ} \mathrm{C}$ for $6 \mathrm{~h}$ under constant illumination. Cercariae shed from infected snails were collected and placed into $1.5 \mathrm{ml}$ tubes for DNA extraction. Due to difficulties with genotyping individual M. novaezealandensis cercariae, approximately 50100 cercariae were pooled from each snail for genetic analysis. Two samples were initially collected from each snail and 2 additional samples were collected from each snail 7 days later. The genotypes of pooled cercariae were determined for 5 microsatellite loci (Mno-1, Mno-2, Mno-28, Mno-30, and Mno-47) as described by Keeney et al. (2006), providing sufficient resolution for the identification of distinct genetic clones (Keeney et al. 2007 a). Snails whose pooled cercariae DNA samples did not possess more than 2 alleles at any locus were treated as having single-genotype infections (corroborated by postinfection genotyping).

\section{Amphipod infections}

Two pairs of parasite genotypes were combined from specific snails harbouring single-genotype infections for experimental infections (genotype A paired with genotype $\mathrm{B}$, genotype $\mathrm{C}$ paired with genotype $\mathrm{D})$. In addition, 2 snails infected with $2 M$. novaezealandensis genotypes each were left unpaired (1 snail shedding genotypes $\mathrm{E}$ and $\mathrm{F}$ and 1 snail shedding genotypes $\mathrm{G}$ and $\mathrm{H}$ ) and used to infect amphipods. This was done to increase the number of mixed genotype infections for growth analyses as the requirement of 2 specific snails shedding sufficient cercariae on the same day could have limited our success in setting up double infections. All mixed infections consisted of genetic clones that differed by 
Table 1. List of experimental treatment combinations

\begin{tabular}{lcll}
\hline \hline Series & Tank & Genotype(s) & Dosage \\
\hline 1 & 1 & G,H* & Low \\
1 & 2 & G,H* & Low \\
1 & 3 & C & Low \\
1 & 4 & C & Low \\
1 & 5 & A & Low \\
1 & 6 & A & Low \\
1 & 7 & C,D & Low \\
1 & 8 & C,D & Low \\
1 & 9 & B & Low \\
1 & 10 & B & Low \\
1 & 11 & A & High \\
1 & 12 & A & High \\
1 & 13 & D & Low \\
1 & 14 & A,B & Low \\
1 & 15 & A,B & Low \\
2 & 16 & E,F* & High \\
2 & 17 & G,H* & High \\
2 & 18 & A,B & High \\
2 & 19 & B & High \\
2 & 20 & E,F* & High \\
2 & 21 & E,F* & Low \\
2 & 22 & E,F* & Low \\
2 & 23 & A,B & High \\
2 & 24 & B & High \\
\hline \hline
\end{tabular}

* Denotes infections involving snails with doublegenotype infections that were not included in analyses of cercariae infection success or amphipod mortality.

at least $50 \%$ of their alleles; this is consistent with patterns of mixed infections seen in naturally infected amphipods (Keeney et al. 2007 b). Data generated from amphipods infected by snails harbouring $2 M$. novaezealandensis genotypes (genotypes E, F, $\mathrm{G}, \mathrm{H}$ ) were not included in analyses of cercariae success or amphipod mortality as the exact number of each parasite genotype used during infection of amphipods was not quantified.

For each pair of parasite genotypes, amphipods were infected with either a low (6 total cercariae/ amphipod) or high (12 total cercariae/amphipod) infection dose, and either cercariae from one genotype in the pair, the other genotype in the pair, or equal numbers ( 3 and 3 , or 6 and 6 ) of cercariae from both genotypes (Table 1). High and low doses were used to produce a range of parasite infection intensities within hosts that reflect natural intensities (Fredensborg et al. 2004; Keeney et al. 2007 b). Due to insufficient cercariae production, we were not able to infect amphipods with high doses of genotypes $\mathrm{C}$ and D.

For each treatment combination, we attempted to infect 2 sets of 96 amphipods. Uninfected amphipods were collected from Hooper's Inlet, South Island, New Zealand where the snail first intermediate host of $M$. novaezealandensis does not occur; no infected amphipods have ever been found from that locality (Fredensborg et al. 2004). For infections, snails were placed into $60 \mathrm{~mm}$ Petri dishes containing $0 \cdot 22 \mu \mathrm{m}$ filtered seawater at $25{ }^{\circ} \mathrm{C}$ for approximately $1 \mathrm{~h}$ under constant illumination. Cercariae obtained during that time were transferred with a $200 \mu \mathrm{l}$ pipette to individual wells in 96 -well plates ( $250 \mu 1$ volume) each containing an uninfected amphipod in $75 \mu \mathrm{l}$ of seawater. Amphipods were then incubated at $25{ }^{\circ} \mathrm{C}$ for $5 \mathrm{~h}$ under constant illumination. After incubation, each set of 96 amphipods was placed into a 1 litre tank of seawater containing sea lettuce (Ulva lactuca) and an airstone. Tanks were arranged randomly on a laboratory bench and left at room temperature throughout the study. Two tanks of 96 control amphipods were manipulated in the same manner with water pipetted into their wells instead of cercariae. On each day of infection, 30 cercariae were measured under a binocular microscope (length and width of body) from each snail used to estimate initial cercariae sizes. Experimental infections were conducted in 2 series with series 1 running from 15 November 2006 to 11 December 2006 and series 2 running from 17 January 2007 to 23 February 2007. Because of the large numbers of cercariae required for infections, the selection of specific snails each day was often dictated by the ability of the snails to produce sufficient cercariae.

Fourteen days after infection (a time-period sufficient for substantial parasite growth, but not complete encystment and development (Martorelli et al. 2004)), the number of amphipods alive in each tank was counted and the sex and length of each amphipod was recorded. Each amphipod was dissected and the number of $M$. novaezealandensis metacercariae was recorded. The maximum length and width of each metacercaria was measured and individual metacercariae were placed in $1.5 \mathrm{ml}$ tubes for DNA extraction. For DNA extraction, individual metacercariae were placed in $400 \mu \mathrm{l}$ of $5 \%$ chelex containing $0.1 \mathrm{mg} / \mathrm{ml}$ proteinase $\mathrm{K}$, incubated at $60{ }^{\circ} \mathrm{C}$ for $2-8 \mathrm{~h}$ and boiled at $100{ }^{\circ} \mathrm{C}$ for $8 \mathrm{~min}$. To identify specific genotypes, the genotypes at 2 microsatellite loci (combinations of Mno-1, Mno-28, Mno-30, and Mno-47) were determined for all individual M. novaezealandensis metacercariae collected from mixed-genotype infections and for a subset of 25 metacercariae per single-genotype infection tank (all individual metacercariae matched the expected cercariae genotypes) as described in Keeney et al. (2006).

\section{Data analysis}

For host mortality and infectivity analyses, parasites were grouped according to whether they came from amphipods that were exposed to single- or doublegenotype infection. For within-host growth analyses, parasites were grouped according to the genetic diversity (single- or double-genotype infection) of metacercariae sharing amphipod hosts, and only 
amphipods with 2 or more metacercariae were included. Parasites from amphipods in the initial double-genotype treatments that were successfully infected by a single genotype were included in the single-genotype group.

All statistical analyses were performed using SPSS 16.0 for Windows. Two-way analysis of variance (ANOVA) was used to examine the influence of infection treatment (single- $v$ double-genotype) and cercariae dose (low $v s$ high) on the percentage of dead amphipods per tank. A $t$-test was used to compare amphipod mortality between treatments and controls. Mann-Whitney U (M-W) tests were used to examine the influence of infection dose (high $v$ s low) on the number and percentage of cercariae successfully infecting amphipods in single, double, and combined (single and double infection results pooled) infections. To examine the effects of genetic diversity on cercariae infection success, the percentage of cercariae of each genotype and of all genotypes infecting amphipods was compared between amphipods exposed to single- and double-genotype cercariae with M-W tests.

Two measurements were used to examine the influence of several factors, including genetic diversity, on within-host parasite growth. First, we used parasite size as an estimate of parasite growth and compared growth rates within amphipods infected with either 1 or 2 parasite genotypes. Parasite size was calculated as the area of an ellipse $(\pi \mathrm{LW}) / 4$, with $\mathrm{L}=$ parasite length and $\mathrm{W}=$ parasite width. Because this growth estimate could be biased if parasite size at the time of infection was not consistent, we calculated the size (not including tail) of 30 cercariae shed by each snail each day they were used for infections and examined differences in cercariae size based on genotype and date of shedding independently with Kruskal-Wallis (K-W) tests. After detecting significant differences in cercariae size among genotypes and within genotypes from different days, the mean size of cercariae shed by the snail on the day of infection was subtracted from each post-infection metacercariae body size. These corrected sizes (parasite growth) were used in our models. Second, we calculated the coefficient of variation $(\mathrm{CV})$ in parasite growth (CV=100*standard deviation/ mean) within each amphipod and used these in our models to determine what factors cause greater variation in parasite utilization of host resources.

Two sets of generalized linear models were used to examine the effects of several variables on the response variables parasite growth and CV. Models incorporated gamma distributions, log links, and maximum likelihood estimated scale parameters, and the following potential explanatory variables were examined: single- or double-genotype infection (infection), first or second infection series (series), number of parasites within amphipods (\# para), amphipod sex (sex), and amphipod length (length).
For each response variable, all possible models involving at least one of the explanatory variables were analysed for main effects. Model selection for each response variable was based on the lowest Akaike Information Criterion corrected for finite sample sizes (AICc) and facilitated by calculating differences in $\mathrm{AICc}$ values between each model and the model with the lowest AICc score $\left(\Delta_{\mathrm{i}} \mathrm{AICc}\right)$. Models with $\Delta_{\mathrm{i}}$ AICc scores $\geqslant 4$ have considerably less empirical support (Burnham and Anderson, 2002). Akaike weights $\left(w_{\mathrm{i}}\right)$ were calculated to examine the weight of evidence supporting each model as the actual best model in our set of candidates and the evidence in favour of our selected model(s) was calculated as the ratio of Akaike weights $\left(w_{\text {selected model }} / w_{\text {alternative model }}\right.$ or $\left.w_{\mathrm{i}} / w_{\mathrm{j}}\right)$, which provides the relative likelihood of model $\mathrm{i}$ being the actual best model versus model $\mathrm{j}$ (Burnham and Anderson, 2002). Interactions between pairs of main effects were examined in a subset of best models (models with $\Delta_{\mathrm{i}}$ AICc scores $<4$ or $w_{\mathrm{i}} /$ $\left.w_{\mathrm{j}}<10\right)$. All interactions were initially included and sequentially removed if the interaction was not significant and its removal did not raise the AICc value. Significance of main effects and interactions was determined from the best model(s) using $P<0.05$ as the criterion for significance.

\section{RESULTS}

In total, 307 amphipods (148 male, 159 female) survived out of 1632 initially exposed to parasites; mortality analyses are based on these data. No effect on amphipod mortality (mean survival $=18 \cdot 8 \pm 8 \cdot 8 \%$ s.D.) was detected for the main effects infection treatment $\left(F_{1,13}=0.343, P=0.568\right)$ and cercariae dosage $\left(F_{1,13}=0.052, \quad P=0.824\right)$, and there was no significant interaction effect $\left(F_{1,13}=0 \cdot 001, P=\right.$ $0 \cdot 979)$. A significant difference in amphipod mortality was not detected between treatments and controls ( $t$-test $\left.t_{17}=-1 \cdot 169, P=0 \cdot 259\right)$. A significantly higher number of parasites were recovered from amphipods exposed to high versus low parasite doses with single- (M-W test, $Z=-5.692, P<$ $0 \cdot 001)$, double- $(Z=-4 \cdot 740, P<0 \cdot 001)$, and combined $(Z=-7 \cdot 328, P<0 \cdot 001)$ genotype infections. No difference in the percentage of cercariae successfully infecting amphipods was detected between high and low dose treatments with single$(Z=-0 \cdot 886, P=0 \cdot 375)$, double- $(Z=-0.937, P=$ $0 \cdot 349)$, or combined $(Z=-1 \cdot 231, P=0 \cdot 218)$ genotype infections. Genotype A showed a significant decrease in cercariae success in double- versus single-genotype infections $(Z=-2 \cdot 319, P=0 \cdot 020)$ (Fig. 1). Genotype B also displayed a decrease in cercariae success in double- versus single-genotype infections, but this was not statistically significant $(Z=-1 \cdot 453, P=0 \cdot 146)$. Genotypes $\mathrm{C}$ and $\mathrm{D}$ did not show significant differences in cercariae success between treatments (genotype C: $Z=-0 \cdot 070$, 


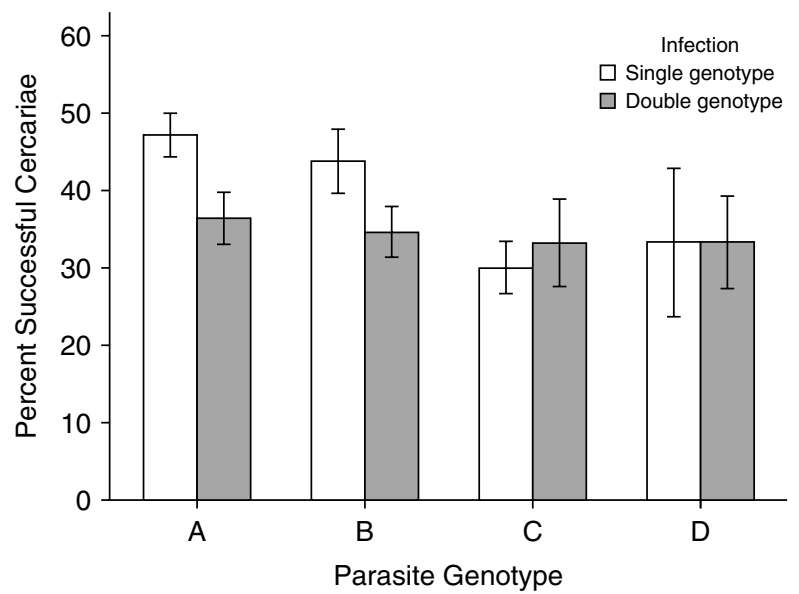

Fig. 1. Percentage of Maritrema novaezealandensis cercariae successfully infecting amphipods in single- and double-genotype infections. Bars represent mean values \pm standard error.

$P=0 \cdot 944 ;$ genotype D: $Z=-0 \cdot 244, \quad P=0 \cdot 807)$. When all genotypes were pooled, an overall decrease in infection success in double-genotype infections was detected, but it was not quite statistically significant $(Z=-1 \cdot 785, P=0 \cdot 074)$. Significant differences in the mean size of cercariae were detected among different genotypes (K-W test, $H=74 \cdot 791$, $P<0 \cdot 001)$ as well as within genotypes shed on different days $(H \geqslant 54 \cdot 029, P<0 \cdot 001)$.

A total of 1200 M. novaezealandensis metacercariae from 265 amphipods (127 male, 138 female) were used in growth analyses. On average, metacercariae were 4-5 times larger at the end of the experiment than they were as cercariae pre-infection. The single best main effects model for parasite growth within amphipods included infection series, single- or double-genotype infection, amphipod sex, and amphipod length as explanatory variables (Table 2). Based on Akaike weight ratios, there was no strong evidence that this model was better than the models with infection series, amphipod sex, and amphipod length $\left(w_{\mathrm{i}} / w_{\mathrm{j}}=2 \cdot 273\right)$, infection series, number of parasites, amphipod sex, and amphipod length $\left(w_{\mathrm{i}} /\right.$ $w_{\mathrm{j}}=2 \cdot 386$ ), or infection series, single- or doublegenotype infection, number of parasites, amphipod sex, and amphipod length $\left(w_{\mathrm{i}} / w_{\mathrm{j}}=1 \cdot 037\right)$ as effects. Interaction effects were examined between all 5 main effects and the inclusion of several interactions significantly improved our final model $(\mathrm{AICc}=$ $2662 \cdot 210, \Delta_{\mathrm{i}} \mathrm{AICc}=-12 \cdot 973$ from best model without interactions). The final model included infection series, amphipod sex, number of parasites, and amphipod length as main effects and infection series*amphipod sex, infection series*number of parasites, number of parasites $*$ amphipod sex, and number of parasites * amphipod length as interaction effects. In this model 2 main effects were significant, with parasites from the second infection series being larger $\left(\chi^{2}=19 \cdot 599, P<0 \cdot 001\right)$ and number of parasites within amphipods being negatively associated with parasite growth $\left(\chi^{2}=5 \cdot 738, P=0 \cdot 017\right)$. Amphipod sex $\left(\chi^{2}=0 \cdot 220, P=0 \cdot 639\right)$ and amphipod length $\left(\chi^{2}=0.435, P=0.509\right)$ were not significant as main effects. Several interactions were also significant. Infection series*amphipod sex indicated parasites in female amphipods from infection series two had disproportionately more growth $\left(\chi^{2}=4 \cdot 616\right.$, $P=0 \cdot 032)$. Infection series $*$ number of parasites indicated that parasites in the second infection series showed less of a decrease in growth as the number of parasites increased $\left(\chi^{2}=8 \cdot 323, P=0 \cdot 004\right)$. Number of parasites $*$ sex revealed that a smaller decrease in growth with increasing number of parasites occurred in female amphipods $\left(\chi^{2}=4 \cdot 369, P=0 \cdot 037\right)$. Lastly, number of parasites $*$ length indicated that a smaller decrease in growth occurred with increasing number of parasites as amphipod size increased $\left(\chi^{2}=4.481, \quad P=0 \cdot 034\right)$. Inclusion of single- or double-genotype infection had minimal influence on the model $(\mathrm{AICc}=2662 \cdot 612)$, and it did not have a significant effect on parasite growth $\left(\chi^{2}=1.773\right.$, $P=0 \cdot 183$ ) or have any significant interactions with other effects.

The single best main effects model for parasite CV included amphipod sex as the only effect (Table 3). This model was only weakly supported as the best model versus numerous other candidate models, including all single effect models, with which it had low Akaike weight ratios. With all of these models, a significant effect on $\mathrm{CV}$ was not detected for any variable (infection series $\chi^{2}=0 \cdot 327, P=0 \cdot 568$; single- or double-genotype infection $\chi^{2}=0.223$, $P=0.637$; number of parasites $\chi^{2}=0.983, P=0 \cdot 321$; amphipod sex $\chi^{2}=2 \cdot 497, \quad P=0.114 ;$ amphipod length $\left.\chi^{2}=1 \cdot 800, P=0 \cdot 180\right)$. For variables included in multiple models with similar support, the highest $\chi^{2}$ and lowest $P$-value have been presented. Inclusion of interactions between main effects did not improve any models and no interactions were significant.

\section{DISCUSSION}

\section{Host mortality and cercariae infection success}

The genetic makeup of parasite infections can have significant effects on the fitness of their hosts. Competition between different parasite genotypes can favour faster utilization of host resources and/or reproduction rates leading to increased virulence (Frank, 1992, 1996). In addition, differences in the cost to the host or ability of the host to defend against multiple parasite genotypes versus single genotypes can reduce host fitness (Read and Taylor, 2001). In this study, we examined fitness effects in terms of host mortality and did not detect any difference in $P$. novizealandiae mortality between those exposed to single- and double-genotype infections. It is 
Table 2. Generalized linear models examining main effects on growth of Maritrema novaezealandensis metacercariae recovered from amphipods

(Dashes (-) represent ratios with numerators of approximately zero.)

\begin{tabular}{|c|c|c|c|c|}
\hline Model effects & $\mathrm{AICc}$ & $\Delta_{\mathrm{i}} \mathrm{AICc}$ & $w_{\mathrm{i}}$ & $w_{\mathrm{i}} / w_{\mathrm{j}}$ \\
\hline Series & $2683 \cdot 428$ & $8 \cdot 245$ & $0 \cdot 005$ & $61 \cdot 713$ \\
\hline Infection & $2891 \cdot 459$ & $216 \cdot 276$ & $0 \cdot 000$ & - \\
\hline \# Para & $2898 \cdot 071$ & $222 \cdot 888$ & $0 \cdot 000$ & - \\
\hline Sex & $2922 \cdot 548$ & $247 \cdot 365$ & $0 \cdot 000$ & - \\
\hline Length & $2929 \cdot 868$ & $254 \cdot 685$ & $0 \cdot 000$ & - \\
\hline Series, Infection & $2681 \cdot 930$ & $6 \cdot 747$ & $0 \cdot 011$ & $29 \cdot 180$ \\
\hline Series, \# Para & $2682 \cdot 058$ & $6 \cdot 875$ & $0 \cdot 010$ & $31 \cdot 109$ \\
\hline Series, Sex & $2684 \cdot 376$ & $9 \cdot 193$ & $0 \cdot 003$ & $99 \cdot 137$ \\
\hline Series, Length & $2684 \cdot 298$ & $9 \cdot 115$ & $0 \cdot 003$ & $95 \cdot 345$ \\
\hline Infection, \# Para & $2868 \cdot 573$ & $193 \cdot 390$ & $0 \cdot 000$ & - \\
\hline Infection, Sex & $2884 \cdot 429$ & $209 \cdot 246$ & $0 \cdot 000$ & - \\
\hline Infection, Length & $2891 \cdot 026$ & $215 \cdot 843$ & $0 \cdot 000$ & - \\
\hline \# Para, Sex & $2893 \cdot 135$ & $217 \cdot 952$ & $0 \cdot 000$ & - \\
\hline \# Para, Length & $2897 \cdot 252$ & $222 \cdot 069$ & $0 \cdot 000$ & - \\
\hline Sex, Length & $2921 \cdot 566$ & $246 \cdot 383$ & $0 \cdot 000$ & - \\
\hline Series, Infection, \# Para & $2680 \cdot 524$ & $5 \cdot 341$ & $0 \cdot 022$ & $14 \cdot 447$ \\
\hline Series, Infection, Sex & $2682 \cdot 656$ & $7 \cdot 473$ & $0 \cdot 008$ & $41 \cdot 951$ \\
\hline Series, Infection, Length & $2682 \cdot 992$ & $7 \cdot 809$ & $0 \cdot 006$ & $49 \cdot 625$ \\
\hline Series, \# Para, Sex & $2683 \cdot 012$ & $7 \cdot 829$ & $0 \cdot 006$ & $50 \cdot 124$ \\
\hline Series, \# Para, Length & $2683 \cdot 274$ & $8 \cdot 091$ & $0 \cdot 006$ & $57 \cdot 140$ \\
\hline Series, Sex, Length & $2676 \cdot 825$ & $1 \cdot 642$ & $0 \cdot 139$ & $2 \cdot 273$ \\
\hline Infection, \# Para, Sex & $2862 \cdot 960$ & $187 \cdot 777$ & $0 \cdot 000$ & - \\
\hline Infection, \# Para, Length & $2866 \cdot 850$ & $191 \cdot 667$ & $0 \cdot 000$ & - \\
\hline Infection, Sex, Length & $2885 \cdot 047$ & $209 \cdot 864$ & $0 \cdot 000$ & - \\
\hline \# Para, Sex, Length & $2894 \cdot 865$ & $219 \cdot 682$ & $0 \cdot 000$ & - \\
\hline Series, Infection, \# Para, Length & $2681 \cdot 253$ & $6 \cdot 070$ & $0 \cdot 015$ & $20 \cdot 801$ \\
\hline Series, Infection, \# Para, Sex & $2681 \cdot 909$ & $6 \cdot 726$ & $0 \cdot 011$ & $28 \cdot 876$ \\
\hline Series, Infection, Sex, Length & $2675 \cdot 183$ & $0 \cdot 000$ & $0 \cdot 316$ & $1 \cdot 000$ \\
\hline Series, \# Para, Sex, Length & $2676 \cdot 922$ & $1 \cdot 739$ & $0 \cdot 133$ & $2 \cdot 386$ \\
\hline Infection, \# Para, Sex, Length & $2864 \cdot 947$ & $189 \cdot 764$ & $0 \cdot 000$ & - \\
\hline Series, Infection, \# Para, Sex, Length & $2675 \cdot 256$ & $0 \cdot 073$ & $0 \cdot 305$ & $1 \cdot 037$ \\
\hline
\end{tabular}

possible that our selection of experimental clones did not cover much of the genetic variation within the source population. Nonetheless, the results at least suggest that if adaptations to the presence of genetically different conspecifics exist in the trematode $M$. novaezealandensis, such as altering host resource utilization, they are not intense enough to create a detectable difference in host mortality.

Parasite transmission success depends on rates of within-host reproduction, which in turn affect virulence (Davies et al. 2002). This can compensate for the detrimental effects to the host, although increased reproduction does not always affect host fitness (Vizoso and Ebert, 2005). The present study examined mortality of second intermediate amphipod hosts; individual $M$. novaezealandensis do not reproduce in this host, but instead grow, encyst, and await predation by a definitive host. Death of the amphipod host before consumption by the definitive host also means death for the parasites. Selection should therefore work against the evolution of strategies causing increased host mortality without compensatory transmission to the final hosts. It is possible that multiple genotype infections influence other aspects of host fitness that are not detectable as differences in survival. Also, our results do not rule out the possibility that the genetic diversity of $M$. novaezealandensis within snail first intermediate hosts, where parasite replication occurs, has a greater effect on host mortality, as in other snail-trematode systems (Davies et al. 2002). It is also possible that increased genetic diversity does influence host mortality when larger numbers of parasite genotypes $(>2)$ infect individual amphipods.

The genetic diversity of parasite infections can also influence the number of parasites that successfully infect a host during exposure, producing variation in parasite load. Total parasite load can decrease as genetic diversity increases (Wedekind and Ruetschi, 2000; Jager and Schjorring, 2006) through direct competition for entry sites or direct and indirect use of the host's immune system against other genotypes (Rauch et al. 2008). In contrast, genetically diverse parasite infections can also lead to increased parasite loads within hosts if the hosts are unable to respond as effectively to diverse infections (Read and Taylor, 2001). In our study, only 1 of the 4 genotypes (genotype A) displayed a significant decrease in 
Table 3. Generalized linear models examining main effects on coefficient of variation in growth of Maritrema novaezealandensis metacercariae recovered from amphipods

\begin{tabular}{|c|c|c|c|c|}
\hline Model effects & $\mathrm{AICc}$ & $\Delta_{\mathrm{i}} \mathrm{AICc}$ & $w_{\mathrm{i}}$ & $w_{\mathrm{i}} / w_{\mathrm{j}}$ \\
\hline Series & $2230 \cdot 528$ & $2 \cdot 310$ & $0 \cdot 042$ & $3 \cdot 174$ \\
\hline Infection & $2230 \cdot 607$ & $2 \cdot 389$ & $0 \cdot 040$ & $3 \cdot 302$ \\
\hline \# Para & $2229 \cdot 911$ & $1 \cdot 693$ & $0 \cdot 057$ & $2 \cdot 331$ \\
\hline Sex & $2228 \cdot 218$ & $0 \cdot 000$ & $0 \cdot 133$ & $1 \cdot 000$ \\
\hline Length & $2228 \cdot 901$ & $0 \cdot 683$ & $0 \cdot 094$ & $1 \cdot 407$ \\
\hline Series, Infection & $2232 \cdot 577$ & $4 \cdot 359$ & $0 \cdot 015$ & $8 \cdot 842$ \\
\hline Series, \# Para & $2231 \cdot 512$ & $3 \cdot 294$ & $0 \cdot 026$ & $5 \cdot 191$ \\
\hline Series, Sex & $2230 \cdot 198$ & $1 \cdot 980$ & $0 \cdot 049$ & $2 \cdot 691$ \\
\hline Series, Length & $2230 \cdot 908$ & $2 \cdot 690$ & $0 \cdot 035$ & $3 \cdot 838$ \\
\hline Infection, \# Para & $2231 \cdot 793$ & $3 \cdot 575$ & $0 \cdot 022$ & $5 \cdot 974$ \\
\hline Infection, Sex & $2230 \cdot 179$ & $1 \cdot 961$ & $0 \cdot 050$ & $2 \cdot 666$ \\
\hline Infection, Length & $2230 \cdot 862$ & $2 \cdot 644$ & $0 \cdot 035$ & $3 \cdot 751$ \\
\hline \# Para, Sex & $2229 \cdot 525$ & $1 \cdot 307$ & $0 \cdot 069$ & $1 \cdot 922$ \\
\hline \# Para, Length & $2230 \cdot 347$ & $2 \cdot 129$ & $0 \cdot 046$ & $2 \cdot 899$ \\
\hline Sex, Length & $2230 \cdot 254$ & $2 \cdot 036$ & $0 \cdot 048$ & $2 \cdot 768$ \\
\hline Series, Infection, \# Para & $2233 \cdot 562$ & $5 \cdot 344$ & $0 \cdot 009$ & $14 \cdot 469$ \\
\hline Series, Infection, Sex & $2232 \cdot 231$ & $4 \cdot 013$ & $0 \cdot 018$ & $7 \cdot 437$ \\
\hline Series, Infection, Length & $2232 \cdot 928$ & $4 \cdot 710$ & $0 \cdot 013$ & $10 \cdot 538$ \\
\hline Series, \# Para, Sex & $2231 \cdot 277$ & $3 \cdot 059$ & $0 \cdot 029$ & $4 \cdot 616$ \\
\hline Series, \# Para, Length & $2232 \cdot 183$ & $3 \cdot 965$ & $0 \cdot 018$ & $7 \cdot 261$ \\
\hline Series, Sex, Length & $2232 \cdot 259$ & $4 \cdot 041$ & $0 \cdot 018$ & $7 \cdot 542$ \\
\hline Infection, \# Para, Sex & $2231 \cdot 381$ & $3 \cdot 163$ & $0 \cdot 027$ & $4 \cdot 862$ \\
\hline Infection, \# Para, Length & $2232 \cdot 220$ & $4 \cdot 002$ & $0 \cdot 018$ & $7 \cdot 396$ \\
\hline Infection, Sex, Length & $2232 \cdot 230$ & $4 \cdot 012$ & $0 \cdot 018$ & $7 \cdot 434$ \\
\hline \# Para, Sex, Length & $2231 \cdot 598$ & $3 \cdot 380$ & $0 \cdot 025$ & $5 \cdot 419$ \\
\hline Series, Infection, \# Para, Length & $2234 \cdot 201$ & $5 \cdot 983$ & $0 \cdot 007$ & $19 \cdot 916$ \\
\hline Series, Infection, \# Para, Sex & $2233 \cdot 303$ & $5 \cdot 085$ & $0 \cdot 010$ & $12 \cdot 711$ \\
\hline Series, Infection, Sex, Length & $2234 \cdot 303$ & $6 \cdot 085$ & $0 \cdot 006$ & $20 \cdot 958$ \\
\hline Series, \# Para, Sex, Length & $2233 \cdot 371$ & $5 \cdot 153$ & $0 \cdot 010$ & $13 \cdot 151$ \\
\hline Infection, \# Para, Sex, Length & $2233 \cdot 470$ & $5 \cdot 252$ & $0 \cdot 010$ & $13 \cdot 818$ \\
\hline Series, Infection, \# Para, Sex, Length & $2235 \cdot 414$ & $7 \cdot 196$ & $0 \cdot 004$ & $36 \cdot 525$ \\
\hline
\end{tabular}

infection success in double- versus single-genotype infections; other genotypes (B, C and D) showed no statistical difference in infection success. As the number of parasites recovered from amphipods increased proportionately with the number of cercariae to which they were exposed, host response factors and/or competition among parasites did not affect infection success regardless of the genetic identity of cercariae. It is possible that competitive effects, either between parasite genotypes or individuals of the same genotype, could become evident if amphipods were exposed to larger numbers of cercariae, but our goal was to mimic natural infection intensities within amphipods which range between 1 and 20 parasites, with mean intensities of approximately 3-6 (Fredensborg et al. 2004; Keeney et al. $2007 \mathrm{~b}$ ). Our results suggest that the diversity of parasite genotypes has a slight influence on infection success in our system but only for specific parasite genotypes. As natural infections of $M$. novaezealandensis in amphipods are characterized by high genetic diversity with only occasional pairs of identical genotypes infecting the same amphipod (Keeney et al. 2007 b), strong selective pressures may not exist for differential host responses or interactions between self and non-self genotypes.

\section{Growth within the host}

We did not detect any effect of genetic diversity of infection on growth or variation in growth among $M$. novaezealandensis within $P$. novizealandiae amphipod intermediate hosts. Therefore, the parasites are not altering their growth rates in response to the presence of non-self genotypes within hosts. Although competition between closely related parasites can theoretically lead to decreased host exploitation and final parasite size (Parker et al. 2003), it may have less of an influence on initial parasite growth rates as studied here. It is also possible that M. novaezealandensis is utilizing its host resources at an optimal level irrespective of infection diversity and that increases in growth rate would lead to subsequent host death (while decreases would have minimal influence on host mortality) and therefore parasite death. This would remove the selective advantage of increasing growth when in the presence of other genotypes, assuming that the parasites are able to identify self and non-self genotypes within amphipod hosts. Selection for differential growth in single- versus double-genotype infections could occur if it coincided with increased transmission of related parasites through alterations in host 
behaviour or morphology (Brown, 1999), but we do not have evidence that this is occurring in this hostparasite system.

Although the genetic diversity of infections did not influence parasite growth within amphipods, other factors did. Parasites within amphipods in the second infection series grew more than the parasites in the first series. This was most likely due to differences in average room temperature between the two series. Below a certain threshold, the growth rate of metacercariae often increases with increasing temperature (Chubb, 1979; Sandland and Goater, 2000). Mean daily temperatures varied significantly between series (series 1 mean temperature \pm S.D. $=$ $12 \cdot 0 \pm 2.7^{\circ} \mathrm{C}$, series 2 mean temperature \pm s.D. $=$ $14 \cdot 4 \pm 2 \cdot 6^{\circ} \mathrm{C} ; t$-test $t_{63}=-3 \cdot 646, P=0 \cdot 001$ ) causing greater growth in series two parasites. This result was not unexpected, and the inclusion of 'series' in our models allowed us to compensate for this difference.

Competition for the limited resources available within a host as well as increased host immune responses to larger numbers of parasites can produce density-dependent decreases in parasite growth (Keymer, 1982; Shostak and Scott, 1993; Poulin, 2007). Indeed, reductions in metacercariae size with increasing parasite load have been detected in several trematode species (Sandland and Goater, 2000; Brown et al. 2003; Fredensborg and Poulin, 2005). Unlike many trematodes, $M$. novaezealandensis metacercariae grow and develop substantially during the first few weeks after infection (Poulin and Latham, 2003; Fredensborg et al. 2004). This is likely to create competition for space as well as nutrients when numerous parasites are present within the host, causing a decrease in the average size of individual parasites. Also, if the degree of exploitation by parasites influences host survival, selection could favour decreased growth with increasing numbers in parasites that require host survival for transmission (Parker et al. 2003). Fredensborg and Poulin (2005) found lower individual mean sizes of fully developed $M$. novaezealandensis metacercariae within heavily-infected crabs; they suggested this could result from resource limitations during initial growth when multiple parasites infect the host, as the slight size differences would not impact host fitness. Our results support differences occurring during early growth, but we do not rule out the possibility that parasite growth strategy could also influence $M$. novaezealandensis during this stage as the smaller amphipod hosts may be more sensitive to parasite growth. Because smaller metacercariae tend to produce fewer eggs as adults (Fredensborg and Poulin, 2005), there could be a trade-off between decreasing virulence and individual parasite fecundity.

Several additional factors influenced the observed density-dependent decrease in parasite growth. There was less of a decrease in growth with increasing parasite number within larger amphipods. This result is consistent with competition among parasites within amphipods causing decreased growth as larger amphipods offer more space and nutrients (Poulin, 1996a), lessening competitive effects. If parasites can detect space or food availability and adjust their growth accordingly, this observation is also consistent with an optimal growth scenario (Parker et al. 2003) in which the parasites, not just resource availability, are controlling their growth rates. A decrease in the extent of density-dependence was also observed when growth rates were higher. It is therefore possible that under certain conditions, such as increased temperature, parasites in higher intensity infections do not display proportionate decreases in host resource utilization despite limited resource availability or consequences to host fitness.

We also detected less of a decrease in growth with increasing parasite number in female amphipods, whose parasites also displayed more growth when growth rates were higher. Male vertebrates often display a higher susceptibility to parasites than females (Poulin, 1996b; Schalk and Forbes, 1997), potentially resulting from the immunosuppressive effects of testosterone (Zuk and McKean, 1996), as well as increased parasite growth (Poulin, 1996c). Although arthropods lack these hormones, other developmental hormones or sexual dimorphisms including behaviour (Zuk and McKean, 1996) can produce differences in parasite susceptibility or within-host parasite growth between sexes. To date, a general sex bias in parasite infections has not been detected in arthropods (Sheridan et al. 2000), though inequality of sizes between sexes often confounds results. It should be stressed that in the present study an increase in overall growth was not detected in female amphipods. There was less of a decrease in growth in females when infection intensity was high than in males, and growth increased disproportionately in females when overall growth rates were higher.

Overall, we did not detect a significant influence of genetic diversity of infection on the host mortality, infectivity, or growth of the marine trematode $M$. novaezealandensis within amphipod hosts. Density-dependent reductions in growth revealed that the number of parasites infecting hosts is more important than their genetic relatedness. Temperature, host size, and host sex also influenced the degree to which density-dependence affects parasite growth. It must be pointed out again that our study included only a small number of clones, and did not necessarily capture the full genetic diversity existing in $M$. novaezealandensis. With this caveat in mind, genetic diversity of infection may play a relatively small role in this host-parasite system compared to the myriad other factors regulating the host-parasite interaction. 
Funding for this research was provided by the Royal Society of New Zealand's Marsden Fund. D.B.K. is grateful to Catherine Grueber for her insightful discussions regarding generalized linear models.

\section{REFERENCES}

Brown, S. P. (1999). Cooperation and conflict in hostmanipulating parasites. Proceedings of the Royal Society of London, B 266, 1899-1904.

Brown, S. P., Hochberg, M. E. and Grenfell, B. T. (2002). Does multiple infection select for raised virulence? Trends in Microbiology 10, 401-405.

Brown, S. P., de Lorgeril, J., Joly, C. and Thomas, F. (2003). Field evidence for density-dependent effects in the trematode Microphallus papillorobustus in its manipulated host, Gammarus insensibilis. Fournal of Parasitology 89, 668-672.

Burnham, K. P. and Anderson, D. R. (2002). Model Selection and Multimodal Inference: A Practical Information-Theoretic Approach, 2nd Edn. SpringerVerlag, Berlin, Germany.

Bush, A. O., Fernández, J. C., Esch, G. W. and Seed, J. R. (2001). Parasitism: The Diversity and Ecology of Animal Parasites. Cambridge University Press, Cambridge, UK.

Chao, L., Hanley, K. A., Burch, C. L., Dahlberg, C. and Turner, P. E. (2000). Kin selection and parasite evolution: higher and lower virulence with hard and soft selection. Quarterly Review of Biology 75, 261-275.

Chubb, J. C. (1979). Seasonal occurrence of helminthes in freshwater fishes. Part II Trematoda. Advances in Parasitology 17, 141-313.

Davies, C. M., Fairbrother, E. and Webster, J. P. (2002). Mixed strain schistosome infections of snails and the evolution of parasite virulence. Parasitology 124, 31-38.

Dugatkin, L. A. (1997). Cooperation Among Animals : An Evolutionary Perspective. Oxford University Press, Oxford, UK.

Frank, S. A. (1992). A kin selection model for the evolution of virulence. Proceedings of the Royal Society of London, B 250, 195-197.

Frank, S. A. (1996). Models of parasite virulence. Quarterly Review of Biology 71, 37-78.

Fredensborg, B. L. and Poulin, R. (2005). Larval helminths in intermediate hosts: does competition early in life determine the fitness of adult parasites? International Fournal for Parasitology 35, 1061-1070.

Fredensborg, B. L., Mouritsen, K. N. and Poulin, R. (2004). Intensity-dependent mortality of Paracalliope novizealandiae (Amphipoda: Crustacea) infected by a trematode: experimental infections and field observations. Fournal of Experimental Marine Biology and Ecology 311, 253-265.

Gower, C. M. and Webster, J. P. (2005). Intraspecific competition and the evolution of virulence in a parasitic trematode. Evolution 59, 544-553.

Griffin, A. S. and West, S. A. (2002). Kin selection: fact and fiction. Trends in Ecology and Evolution 17, $15-21$.

Hamilton, W. D. (1964). The genetical evolution of social behaviour. Fournal of Theoretical Biology 7, 1-52.
Hughes, A. R., Inouye, B. D., Johnson, M. T. J., Underwood, N. and Vellend, M. (2008). Ecological consequences of genetic diversity. Ecology Letters 11, 609-623.

Jager, I. and Schjorring, S. (2006). Multiple infections: relatedness and time between infections affect the establishment and growth of the cestode Schistocephalus solidus in its stickleback host. Evolution 60, 616-622.

Keymer, A. (1982). Density-dependent mechanisms in the regulation of intestinal helminth populations. Parasitology 84, 573-587.

Keeney, D. B., Waters, J. M. and Poulin, R. (2006). Microsatellite loci for the New Zealand trematode Maritrema novaezealandensis. Molecular Ecology Notes 6, 1042-1044.

Keeney, D. B., Waters, J. M. and Poulin, R. (2007a). Clonal diversity of the marine trematode Maritrema novaezealandensis within intermediate hosts: the molecular ecology of parasite life cycles. Molecular Ecology 16, 431-439.

Keeney, D. B., Waters, J. M. and Poulin, R. (2007b). Diversity of trematode genetic clones within amphipods and the timing of same-clone infections. International Fournal for Parasitology 37, 351-357.

Margolis, L., Esch, G. W., Holmes, J. C., Kuris, A. M. and Schad, G. A. (1982). The use of ecological terms in parasitology. Fournal of Parasitology 68, 131-133.

Martorelli, S. R., Fredensborg, B. L., Mouritsen, K. N. and Poulin, R. (2004). Description and proposed life cycle of Maritrema novaezealandensis $\mathrm{n}$. sp. (Microphallidae) parasitic in red-billed gulls, Larus novaehollandiae scopulinus, from Otago Harbor, South Island, New Zealand. Fournal of Parasitology 90, 272-277.

Parker, G. A., Chubb, J. C., Roberts, G. N., Michaud, M. and Milinski, M. (2003). Optimal growth strategies of larval helminths in their intermediate hosts. Fournal of Evolutionary Biology 16, 47-54.

Poulin, R. (1996a). The evolution of life history strategies in parasitic animals. Advances in Parasitology 37, 107-134.

Poulin, R. (1996b). Sexual inequalities in helminth infections: a cost of being a male? American Naturalist 147, 287-295.

Poulin, R. (1996c). Helminth growth in vertebrate hosts: does host sex matter? International fournal for Parasitology 26, 1311-1315.

Poulin, R. (2007). Evolutionary Ecology of Parasites, 2nd Edn. Princeton University Press, Princeton, NJ, USA.

Poulin, R. and Latham, A. D. M. (2003). Effects of initial (larval) size and host body temperature on growth in trematodes. Canadian Fournal of Zoology 81, 574-581.

Rauch, G., Kalbe, M. and Reusch, T. B. H. (2008). Partitioning average competition and extreme-genotype effects in genetically diverse infections. Oikos 117, 399-405.

Read, A. F. and Taylor, L. H. (2001). The ecology of genetically diverse infections. Science 292, 1099-1102.

Sandland, G. J. and Goater, C. P. (2000). Development and intensity dependence of Ornithodiplostomum ptychocheilus metacercariae in fathead minnows 
(Pimephales promelas). Fournal of Parasitology $\mathbf{8 6}$, 1056-1060.

Schalk, G. and Forbes, M. R. (1997). Male biases in parasitism of mammals : effects of study type, host age, and parasite taxon. Oikos 78, 67-74.

Sheridan, L. A. D., Poulin, R., Ward, D. F. and Zuk, M. (2000). Sex differences in parasitic infections among arthropod hosts: is there a male bias? Oikos 88, 327-334.

Shostak, A. W. and Scott, M. E. (1993). Detection of density-dependent growth and fecundity of helminths in natural infections. Parasitology 106, 527-539.
Vizoso, D. B. and Ebert, D. (2005). Mixed inoculations of a microsporidian parasite with horizontal and vertical infections. Oecologia 143, 157-166.

Wedekind, C. and Ruetschi, A. (2000). Parasite heterogeneity affects infection success and the occurrence of within-host competition: an experimental study with a cestode. Evolutionary Ecology Research 2, 1031-1043.

Zuk, M. and McKean, K. A. (1996). Sex differences in parasite infections: patterns and processes. International Fournal for Parasitology 26, 1009-1024. 